\title{
Presence of the Apert canonical S252W FGFR2 mutation in a patient without severe syndactyly
}

\author{
Maria Rita Passos-Bueno, Antonio Richieri-Costa, Andréa L Sertié, Alexander Kneppers
}

\begin{abstract}
Apert syndrome, characterised by craniosynostosis, craniofacial anomalies, and symmetrical syndactyly of the digits (cutaneous and bony fusion), has been associated with two canonical mutations in the FGFR2 gene (S252W, P253R) in the great majority of cases. Since these two alterations have been observed exclusively among these patients, it has been suggested that the S252W and P253R changes may play an important role in the occurrence of syndactyly. In order to verify whether the mutations S252W and P253R could also cause a milder phenotype, without involvement of the limbs, we have screened 22 patients with clinical characteristics compatible with Crouzon or Pfeiffer syndrome for these two particular changes. Surprisingly, we identified a Pfeiffer-like patient with the mutation S252W, and therefore we have shown for the first time the occurrence of one of the canonical Apert mutations without severe abnormalities of the upper and lower extremities.

$(\Im$ Med Genet 1998;35:677-679)
\end{abstract}

Keywords: Apert syndrome; Pfeiffer syndrome; FGFR2 mutations

Apert syndrome is a relatively rare condition characterised by craniosynostosis, craniofacial anomalies, and symmetrical syndactyly of the digits (cutaneous and bony fusion). It has been considered one of the most severe forms of the craniosynostotic syndromes. ${ }^{1-3}$ five Pfeiffer syndrome patients for these two particular changes, according to methods previously reported. ${ }^{7} 1013$

Surprisingly, we identified the S252W change in a Pfeiffer-like subject and this finding was confirmed in two independent DNA samples (fig 1). Subsequently, we sequenced the 5' portion of exon IIIa of this patient which allowed us to confirm the presence of this mutation and to verify that there was no other change in this region of exon IIIa. In addition, we have sequenced FGFR2 exon IIIc of this patient, which was found to be normal (data not shown).

This patient, an African-Brazilian boy, currently aged 4 years (fig 2), is the only affected child of a non-consanguineous, clinically normal couple (mother aged 28 years, father aged 37 years). The pregnancy was normal and delivery was at term by caesarean section. Birth weight was $3900 \mathrm{~g}$ (75th centile) and total body length $52 \mathrm{~cm}$ (50th centile). Craniofacial and upper and lower limb anomalies were noted at birth. Examination at 5 months of age showed an active child. Height was $67.5 \mathrm{~cm}$ (50th centile), weight was $7.9 \mathrm{~kg}$ (50th centile), and OFC was $44 \mathrm{~cm}$ (<50th centile). He had brachycephaly, a prominent forehead, wide anterior fontanelle and metopic suture, large ears, hypertelorism, sparse eyebrows and lashes, flat supraorbital ridges, prominent eyes, broad nasal root, short neck, brachydactyly, bilateral skin syndactyly between fingers 3 and 4, short and broad terminal phalanges, radial deviation of the fingers, club foot, and short toes with tibial deviation. CT head scan showed mild dilatation of the frontal horn of the lateral ventricles and coronal and lambdoid sutures; the anterior cranial fossa was also slightly wider than the posterior. $X$ rays of the

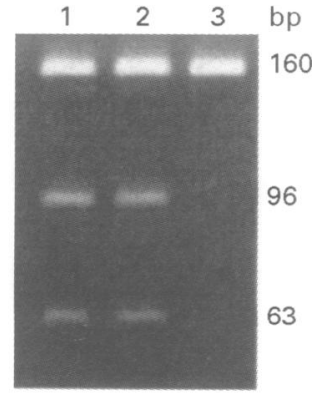

$\mathrm{B}$
Figure 1 Mutational analysis by $\operatorname{SSCP}(A)$ and restriction enzyme digestion (B) of genomic DNA from the Pfeiffer-like patient described here (lane 1), one typical Apert patient with S252W (lane 2), and one control (lane 3). The 5' end of the exon IIIa PCR product was digested with SfiI and analysed on an $8 \%$ acrylamide gel. The S252W mutation cuts, with SfiI, into $96 b p+63$ bp fragments. Primers and PCR conditions were used as

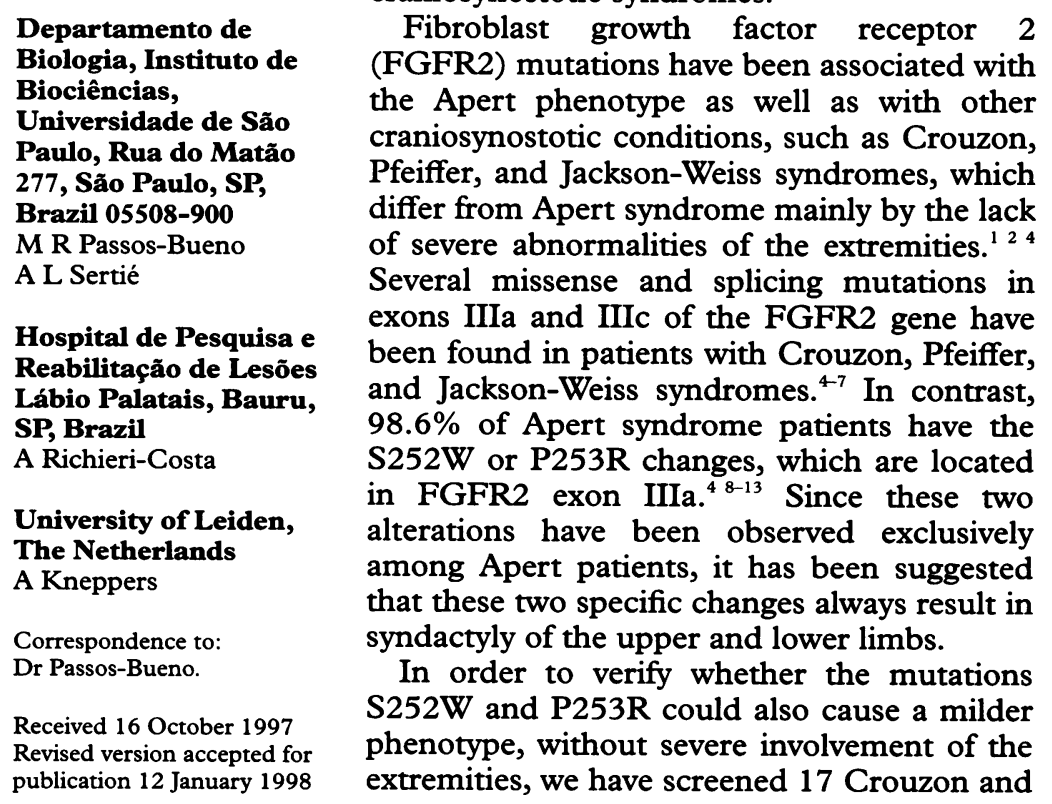

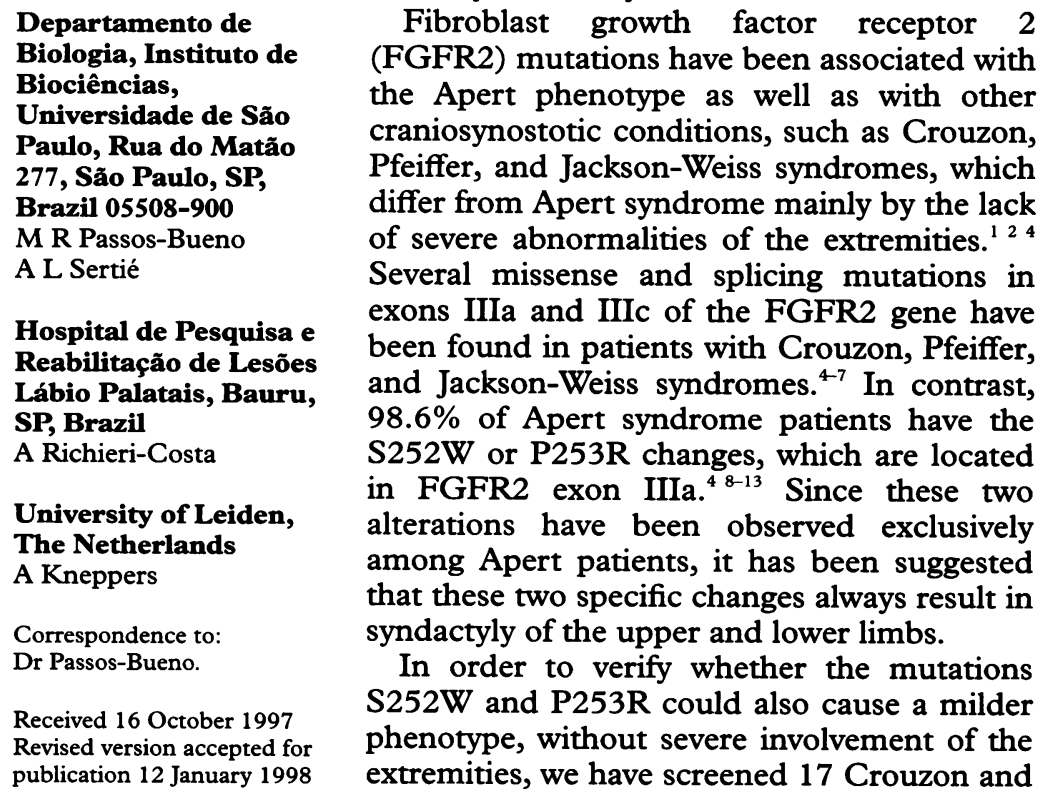

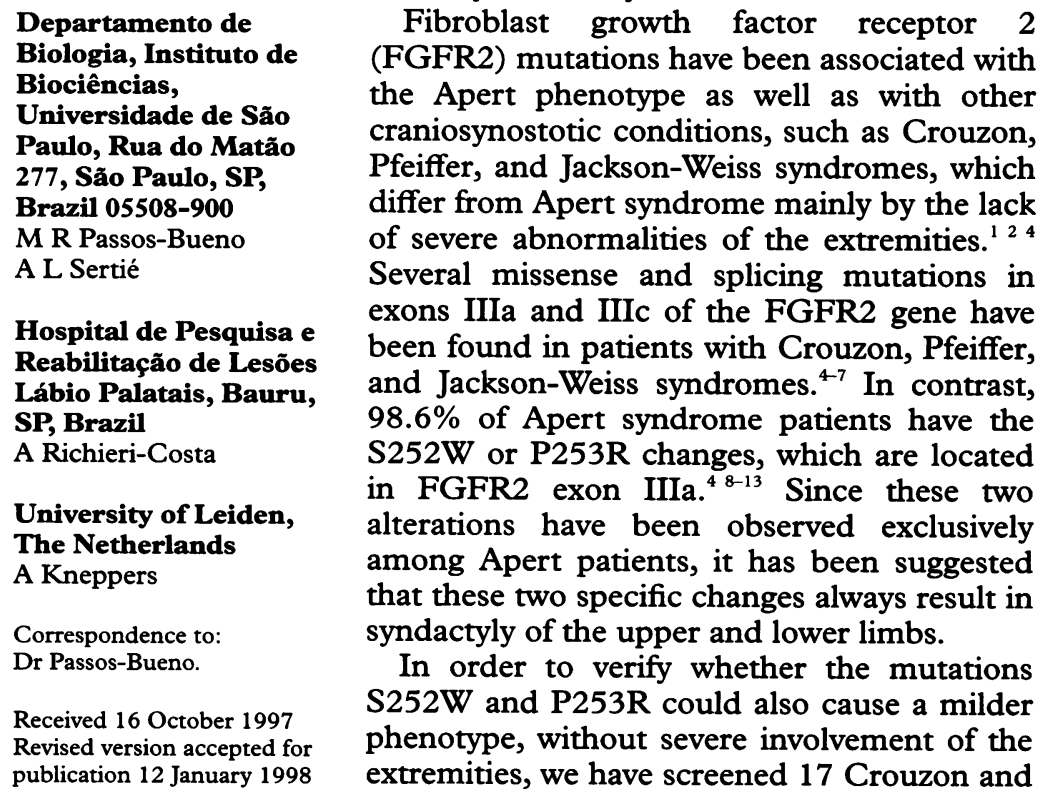

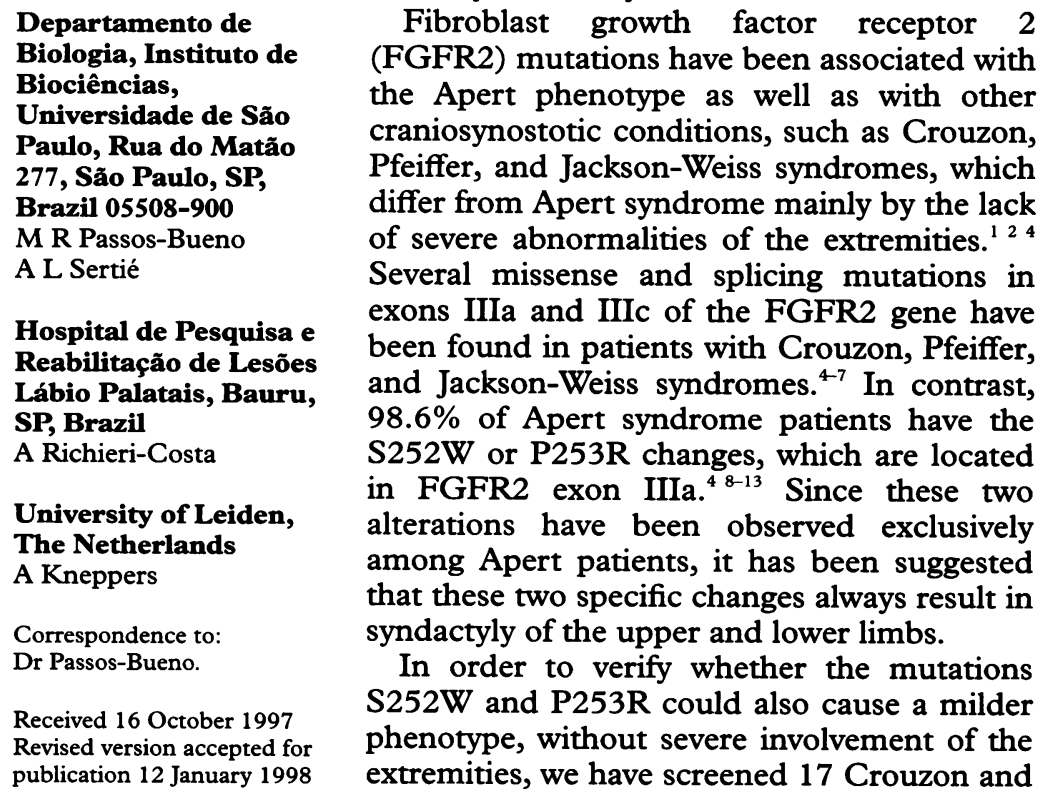

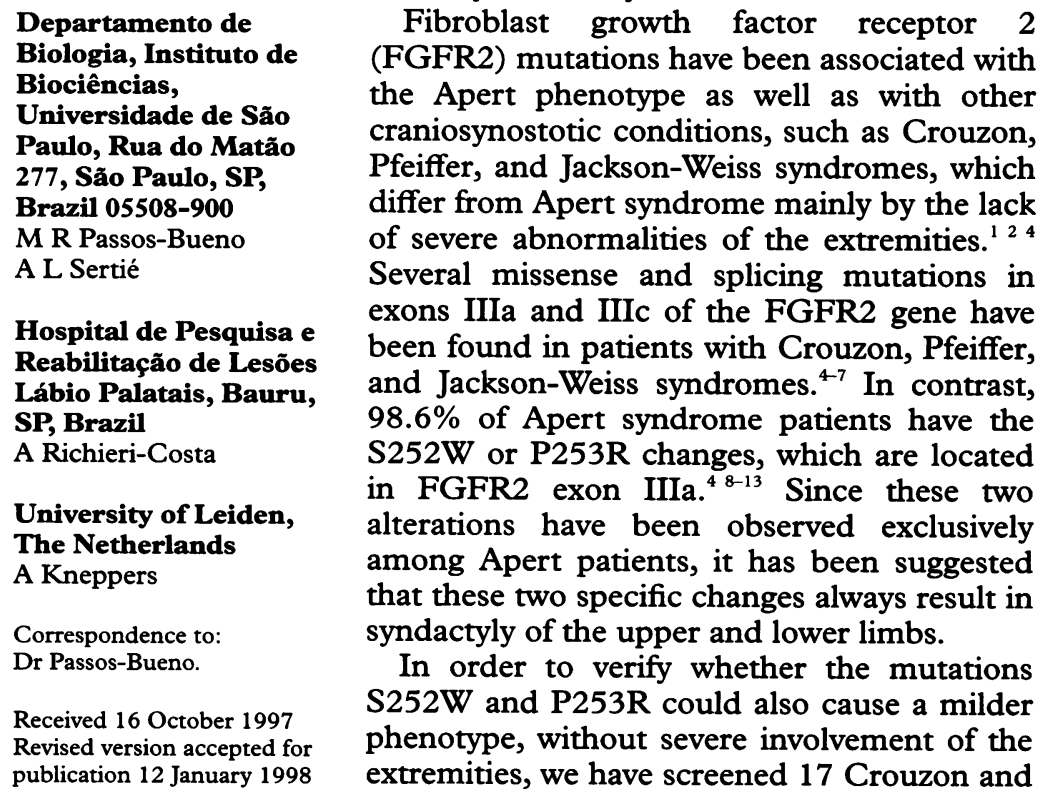

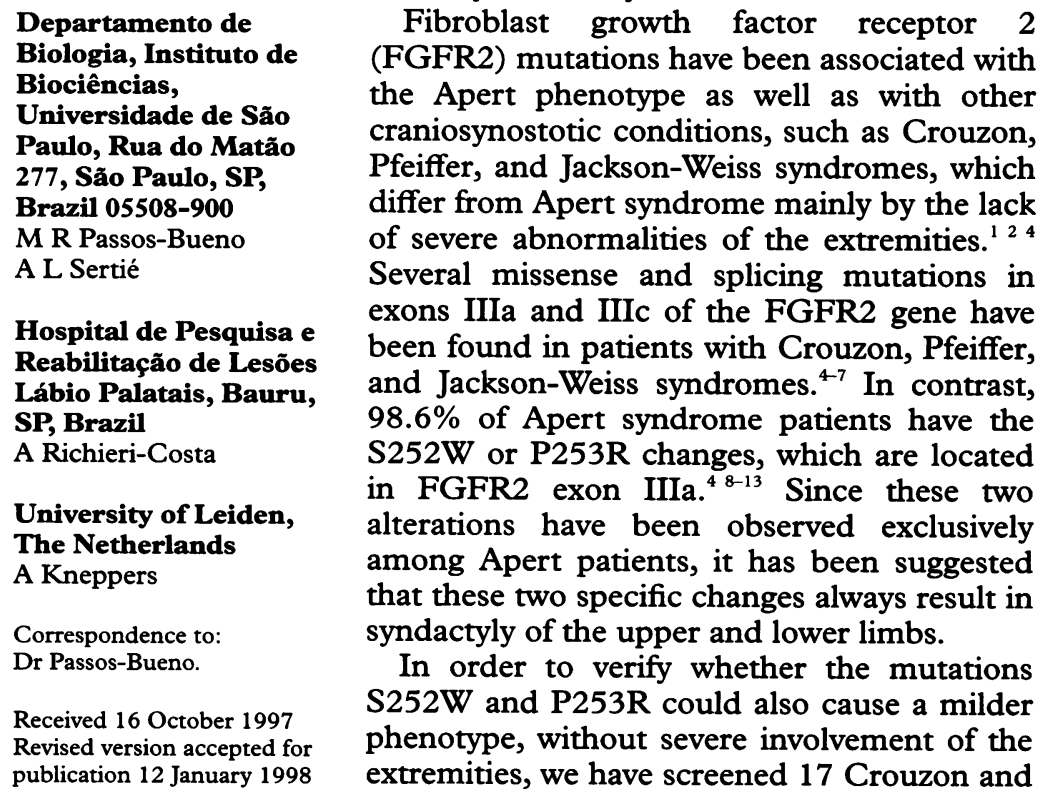

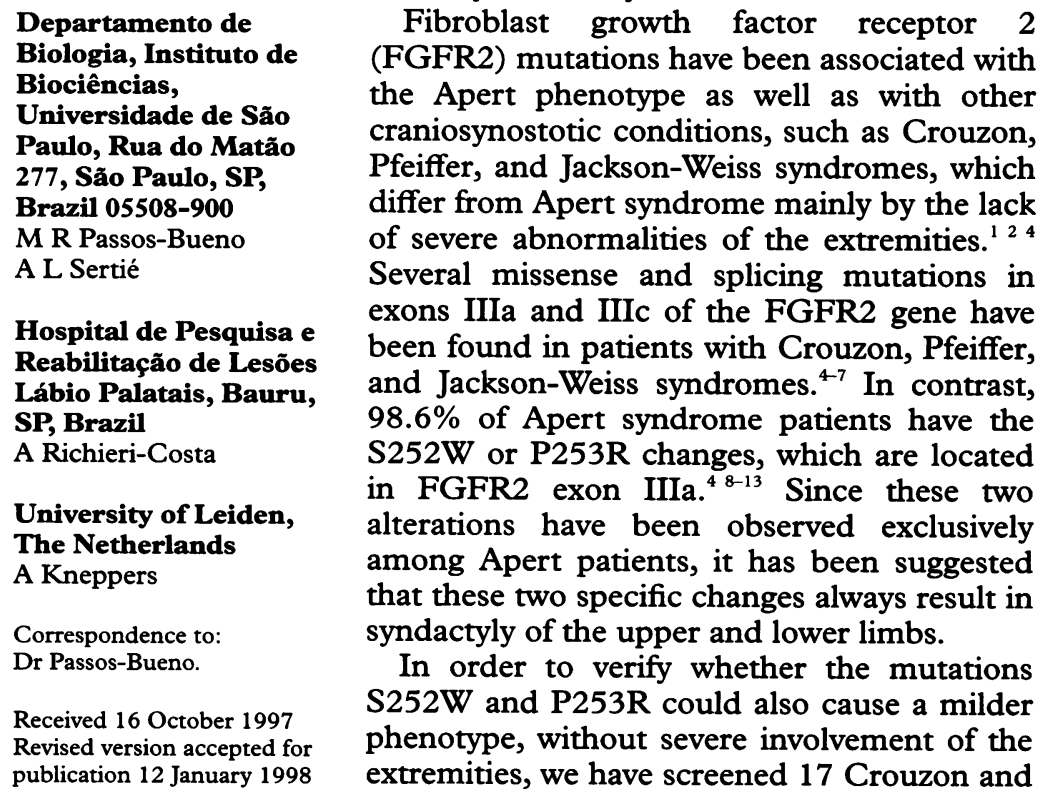

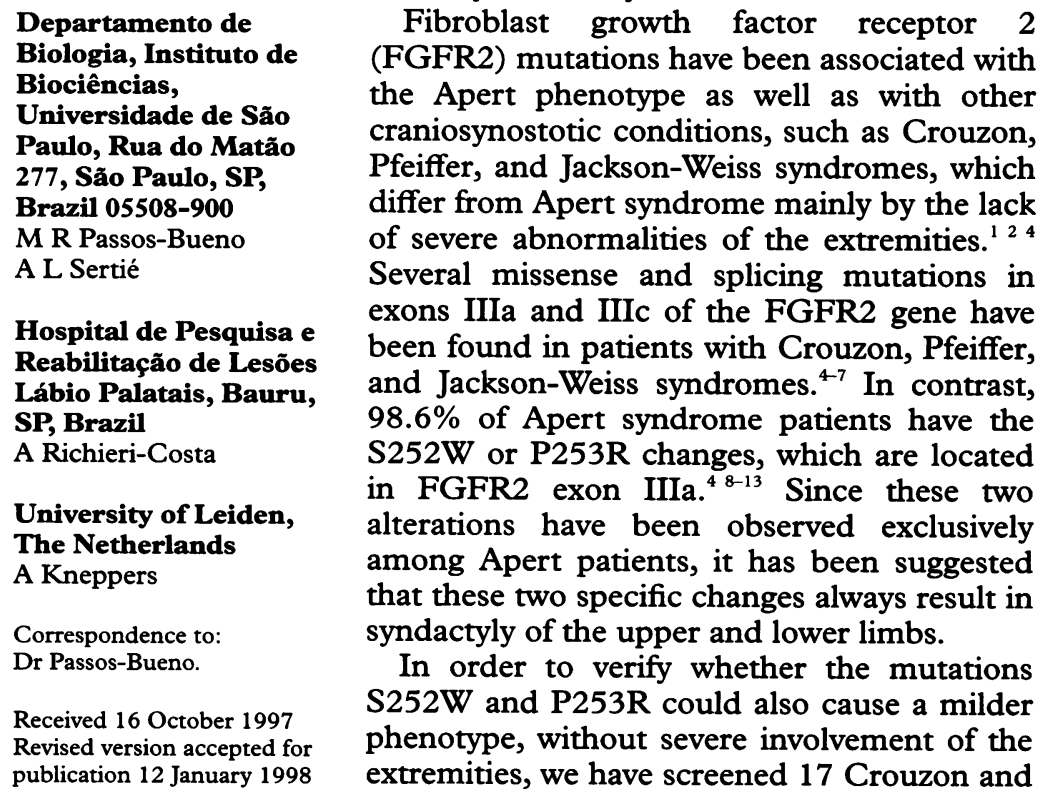

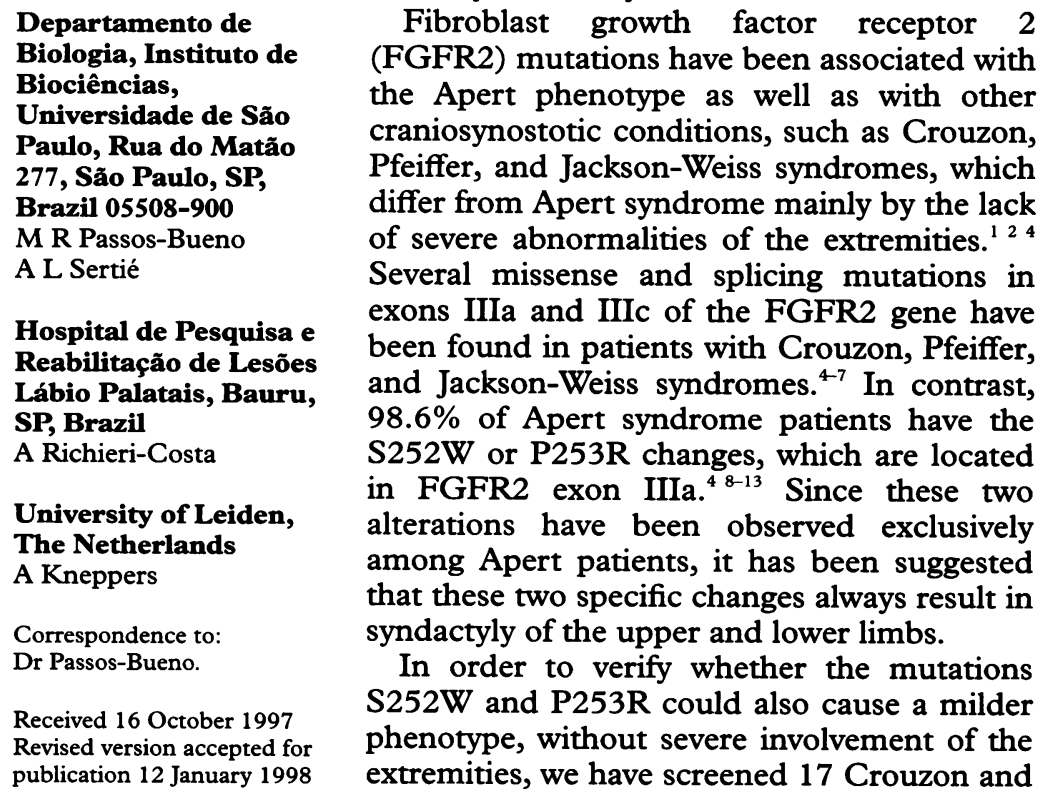

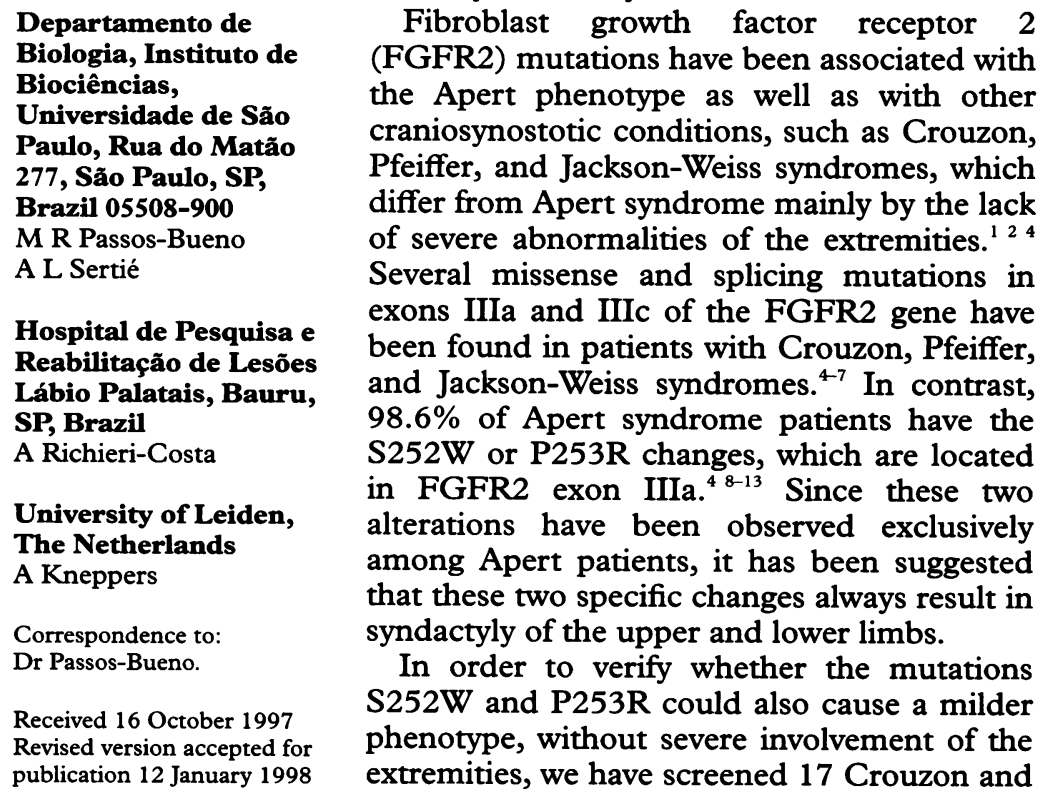

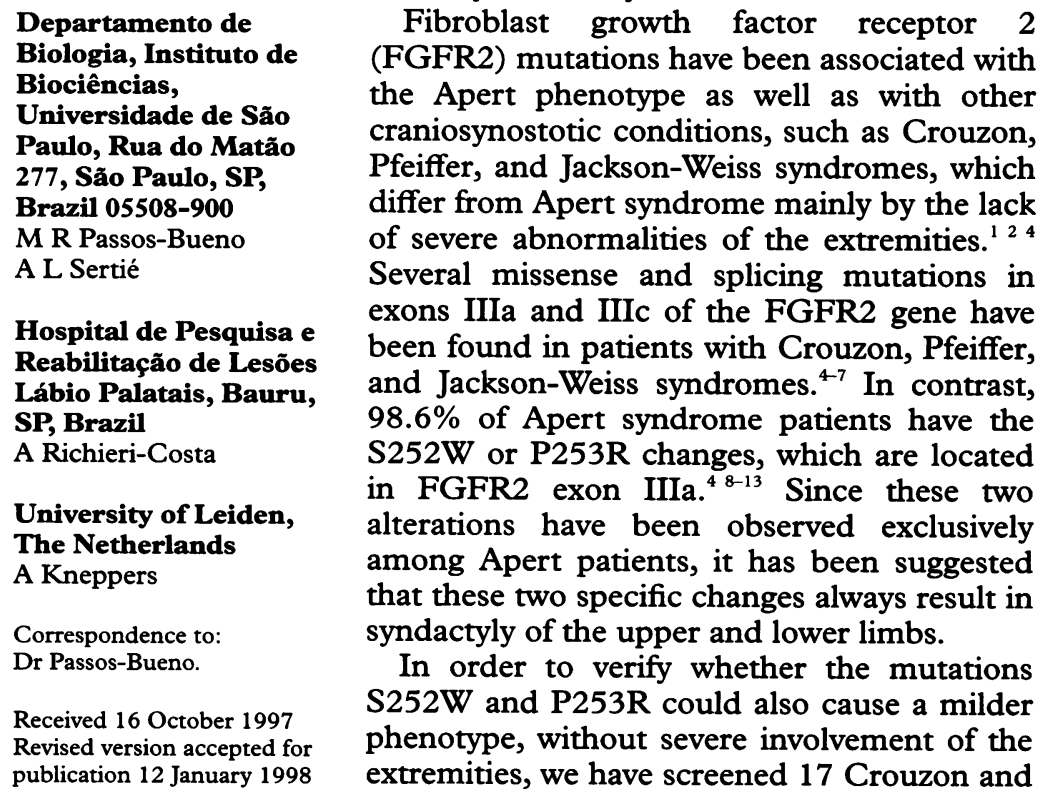

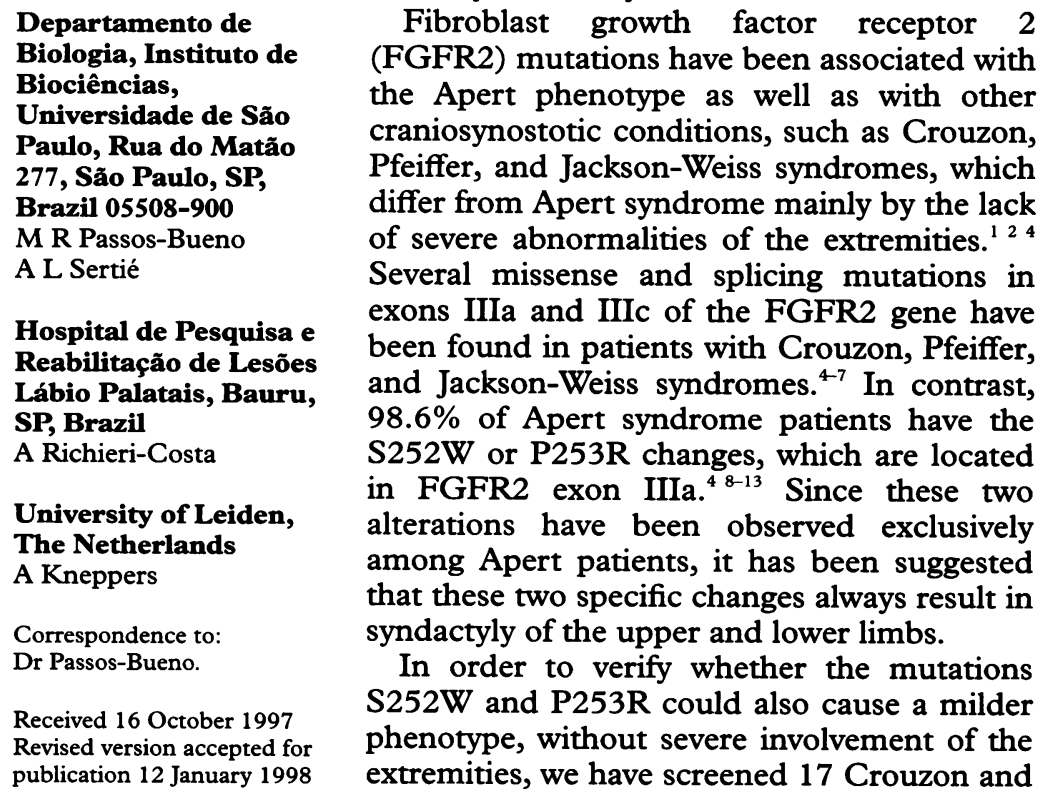

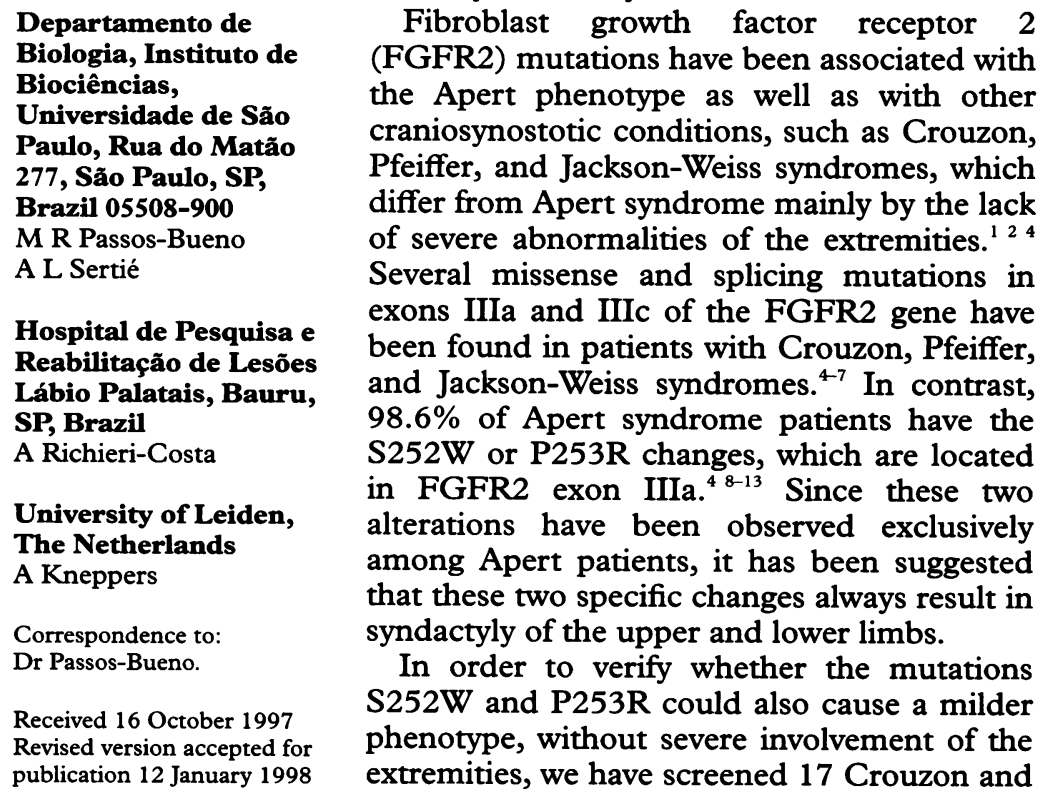

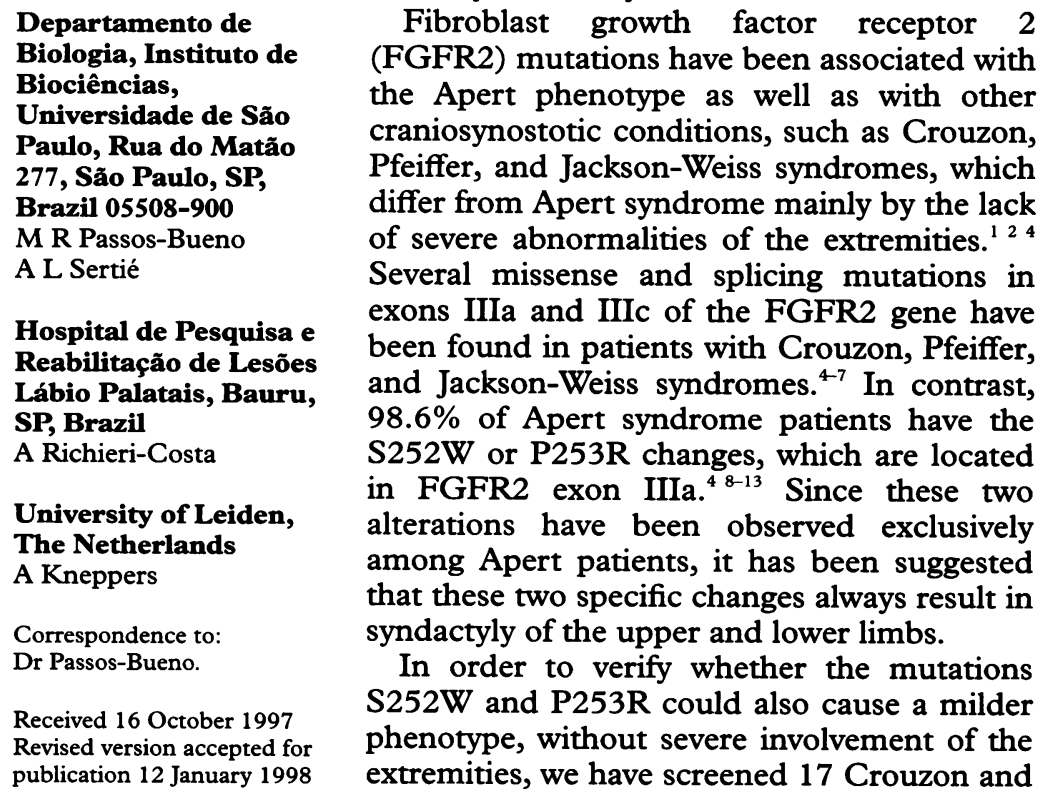

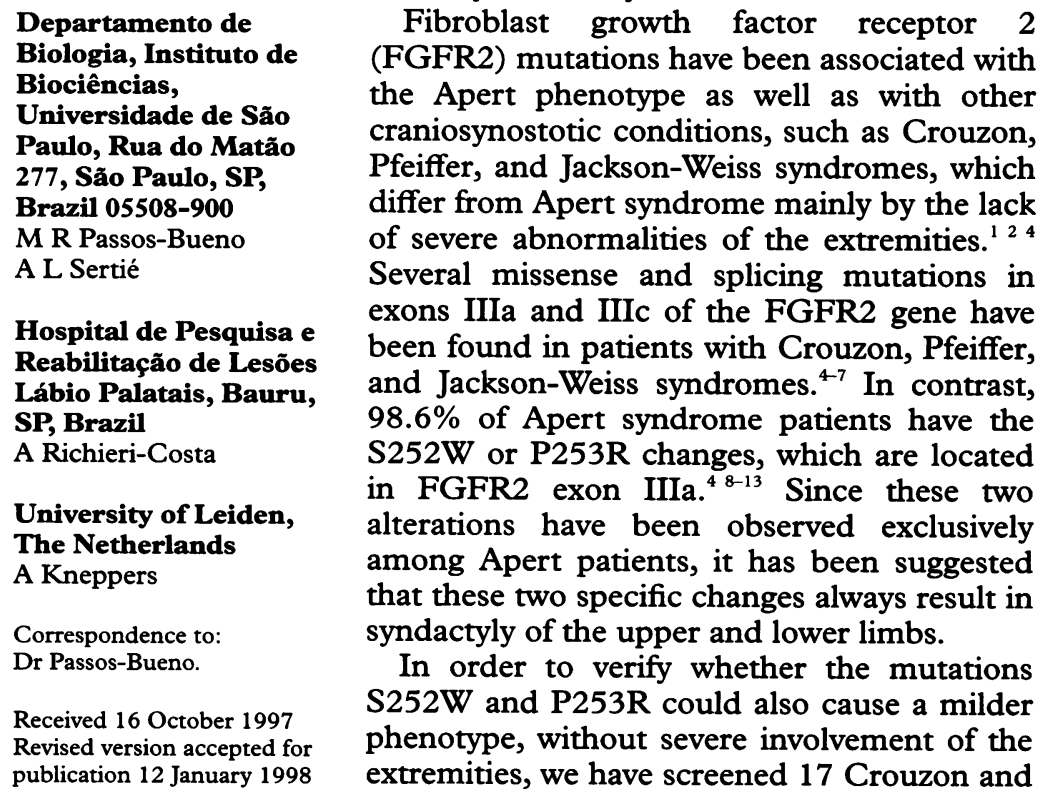

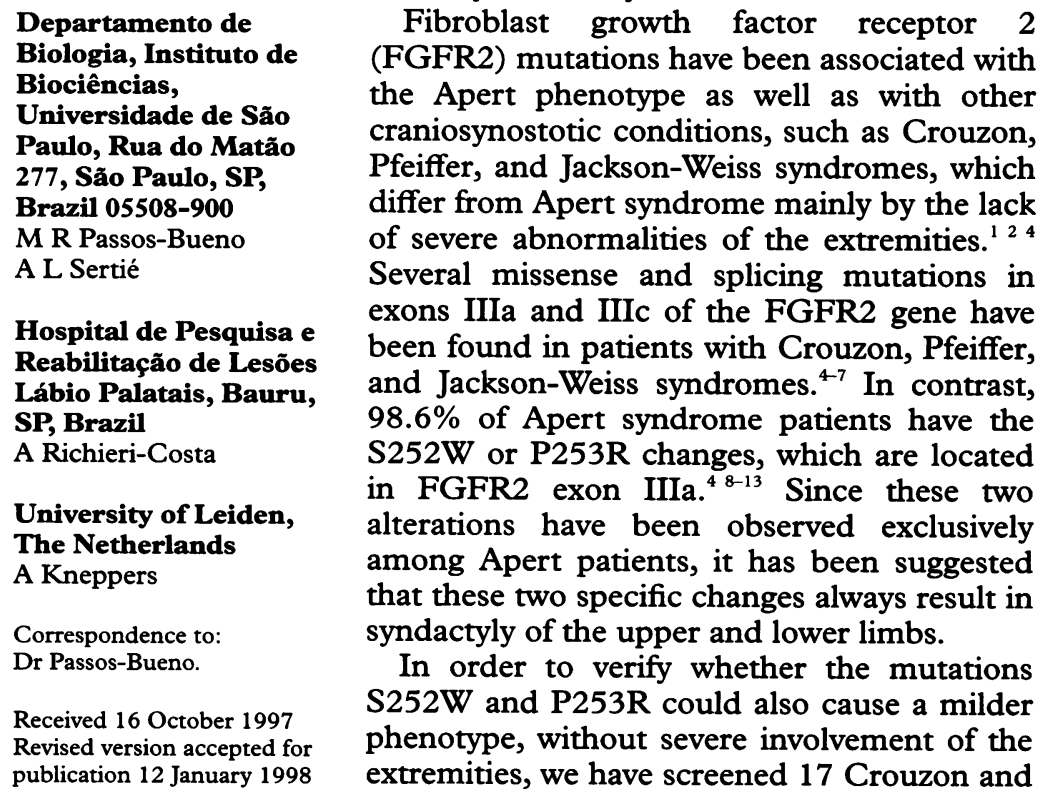

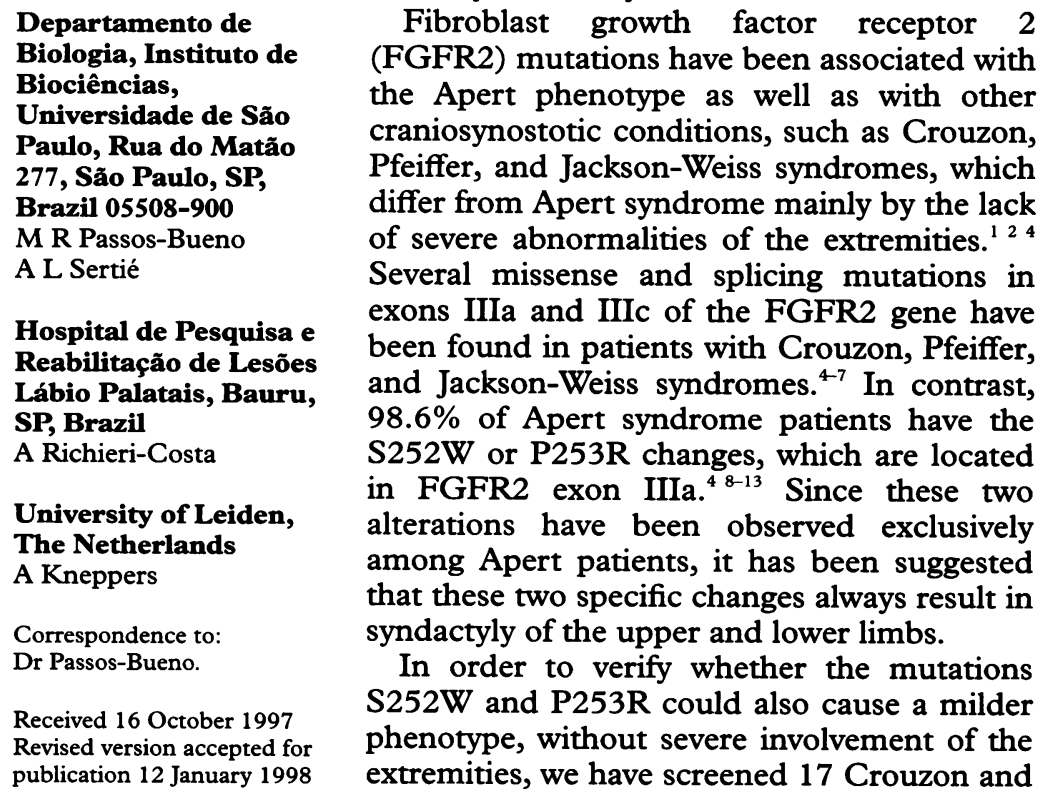

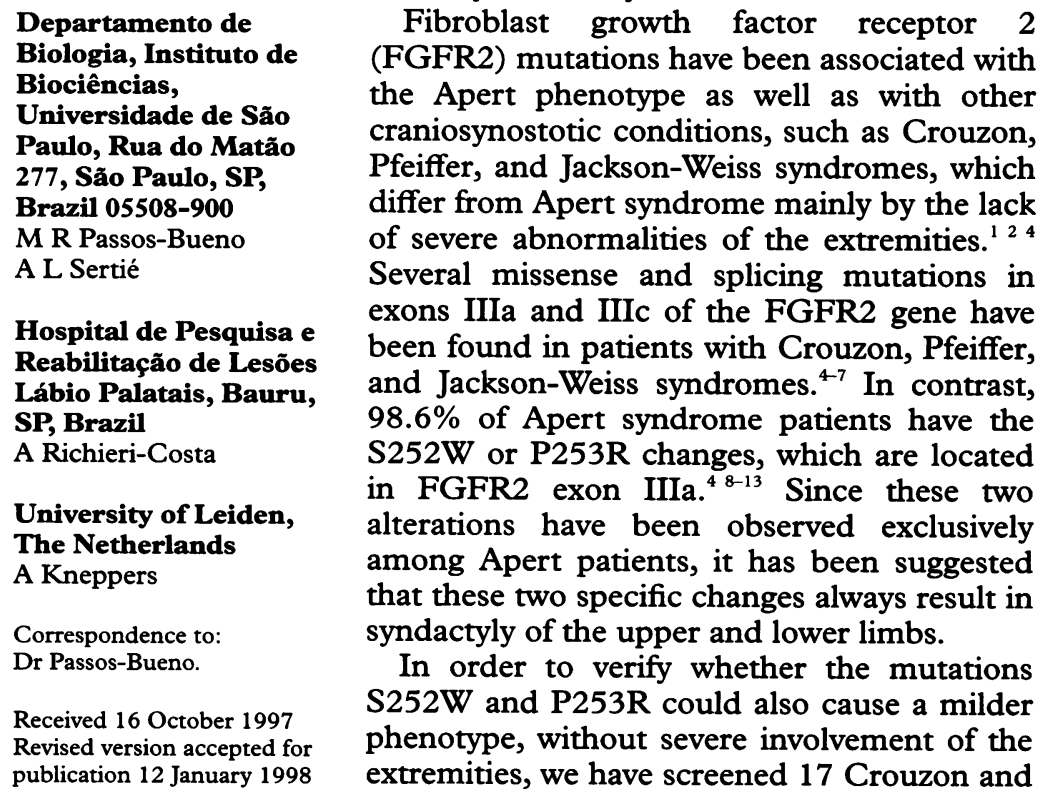

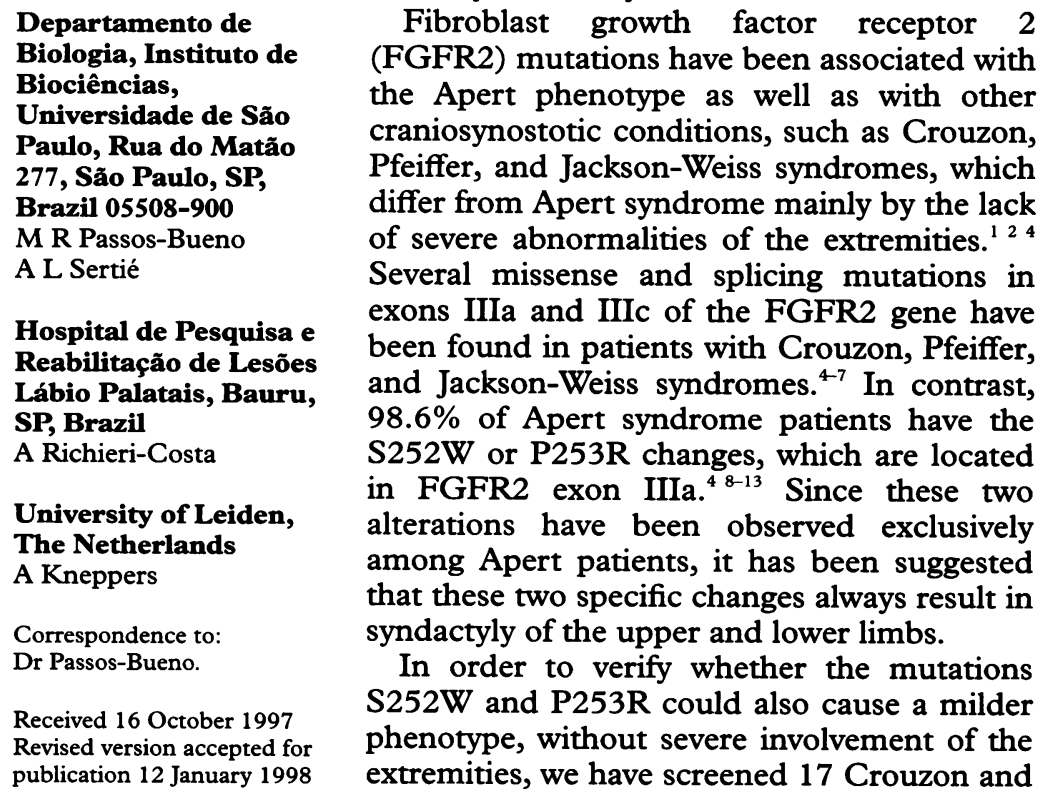

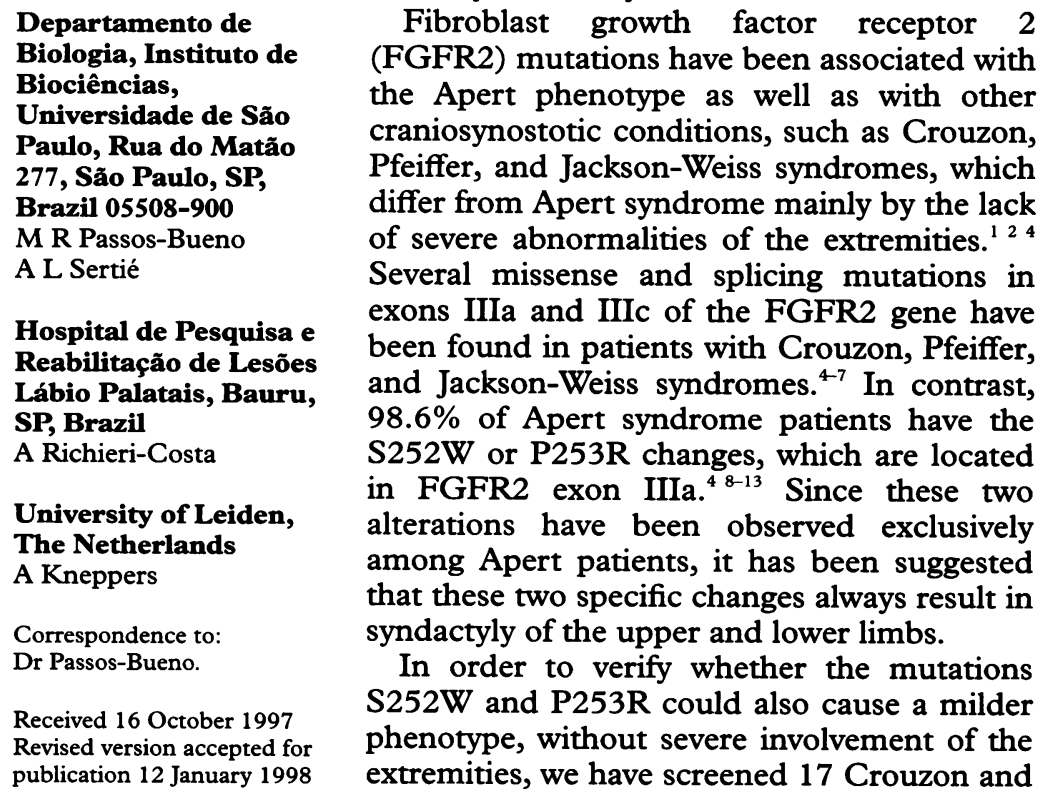

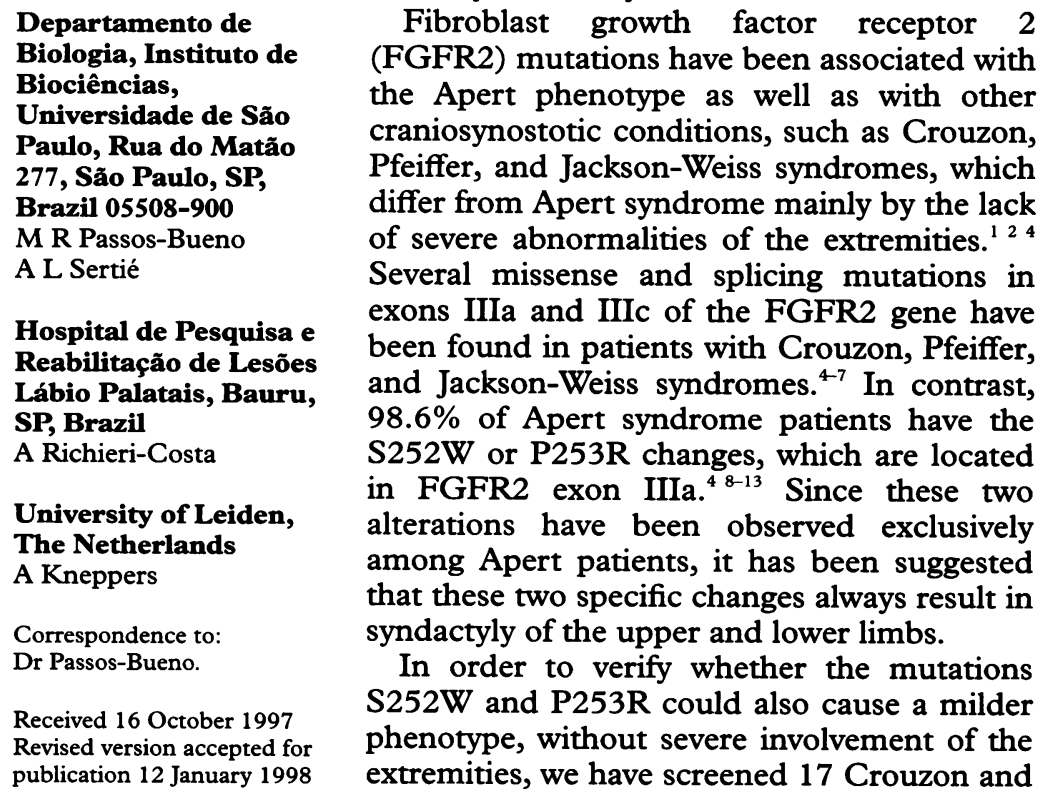

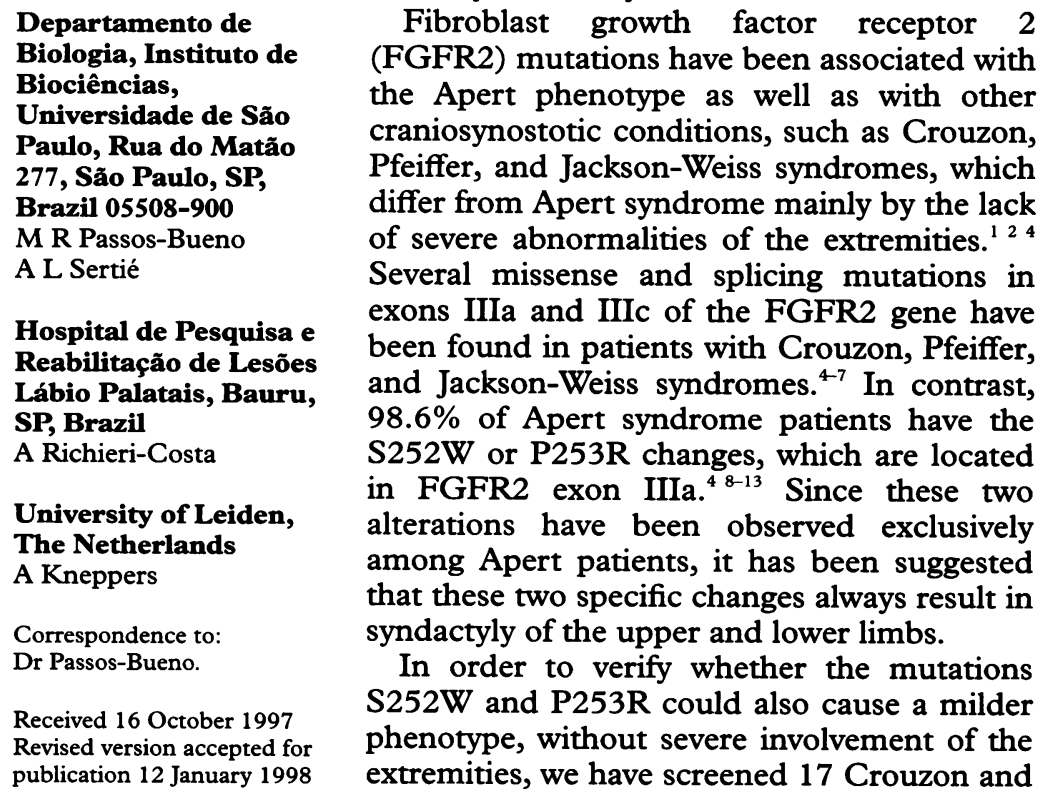

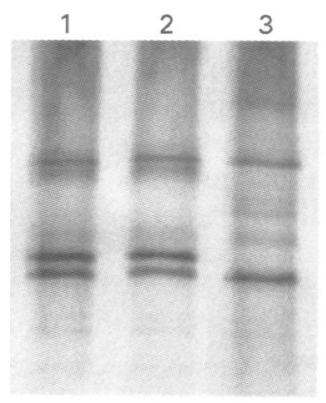

A previously reported by Slaney et al. ${ }^{\prime \prime}$

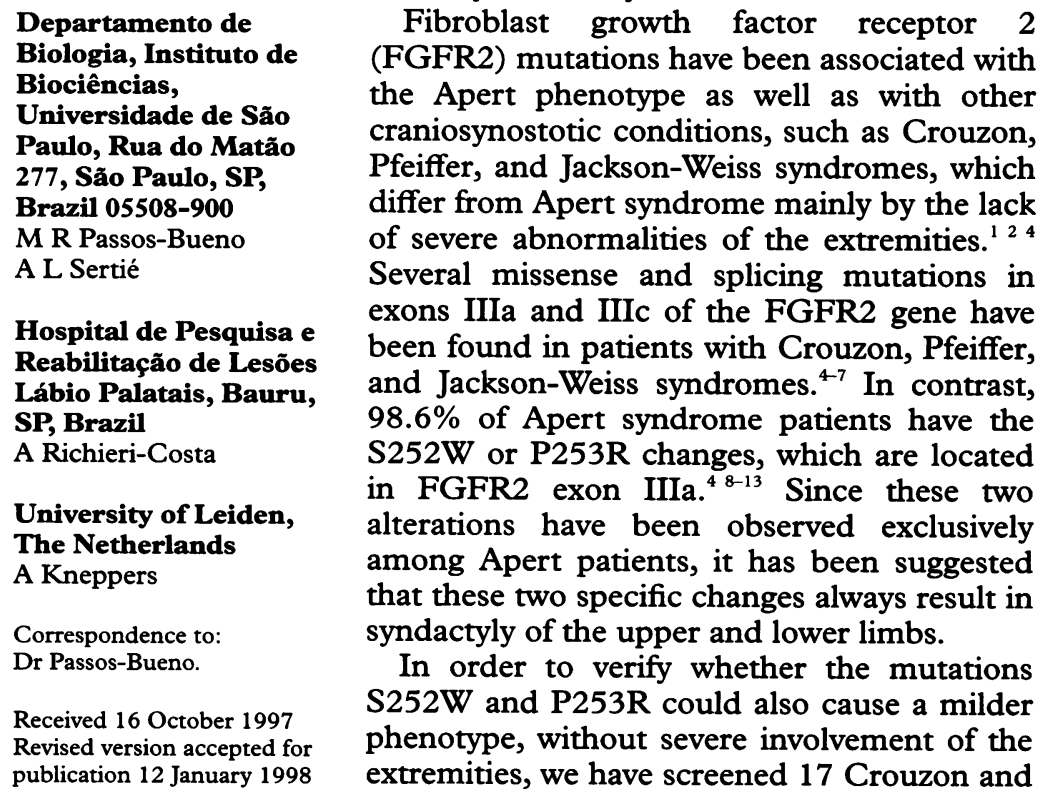

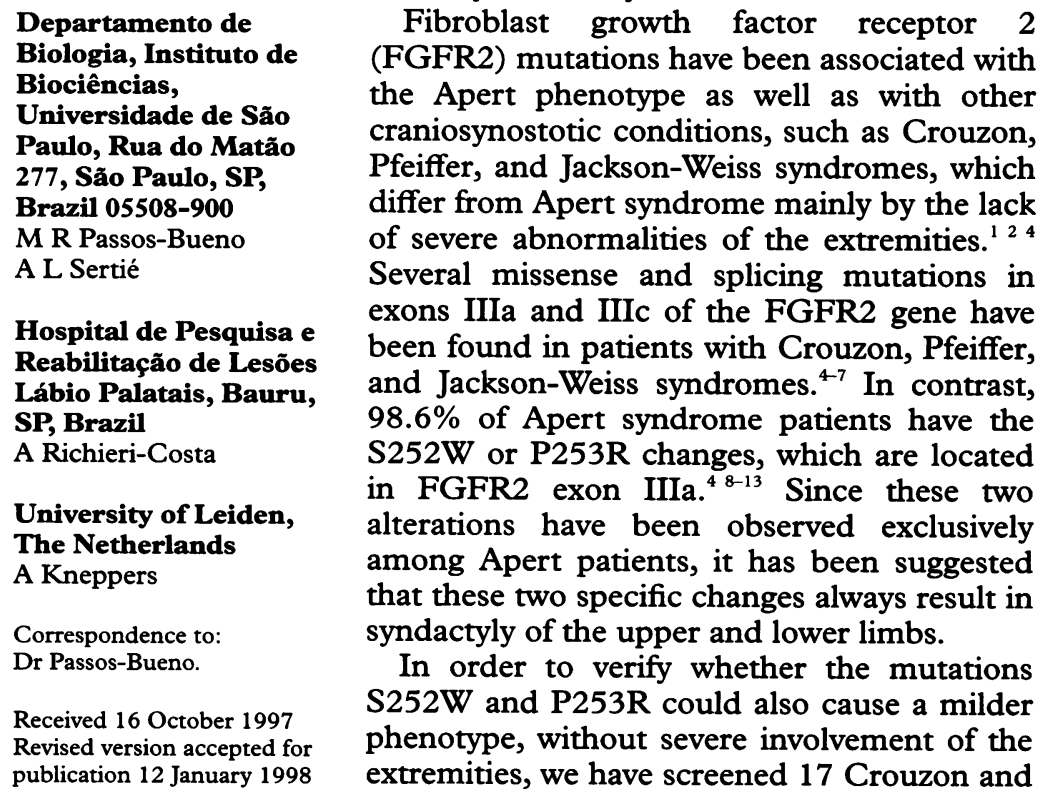

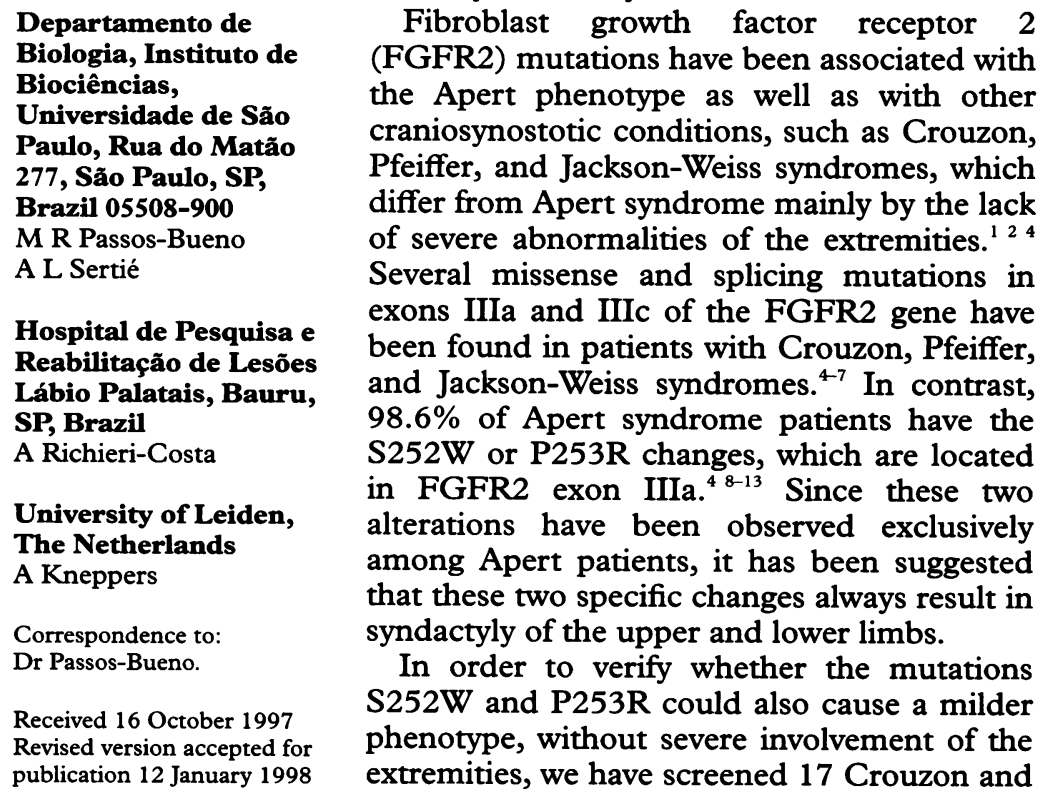



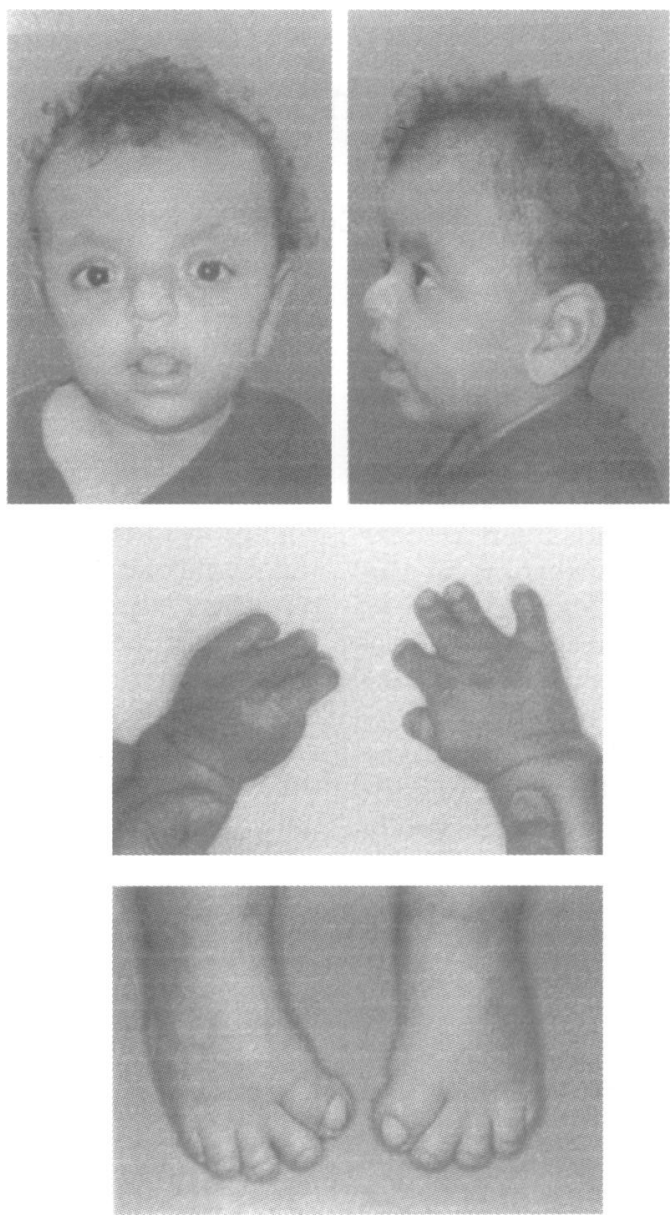

Figure 2 Photographs of the patient with the S252W mutation and a phenotype more compatible with Pfeiffer syndrome. Note the typical facial features of prominent forehead, hypertelorism, and midface hypoplasia. Only soft syndactyly between fingers 3-4 and between toes 2-3 was observed. Hand and foot $x$ ray findings are detailed in the text.

hands showed shortening of the proximal, middle, and distal phalanges of all digits, particularly of the distal phalanges, proximally set and adducted thumbs, and soft tissue syndactyly between fingers 3-4. $X$ rays of the feet showed shortened phalanges of all toes, a short big toe, an increased distance between the first and second toes, and soft tissue syndactyly between toes 2-3. Based on these clinical findings, we considered Pfeiffer syndrome as the most likely diagnosis for this patient (fig 2).

Wilkie et $a l^{\beta}$ first reported that Apert syndrome was caused by mutations S252W or P253R within exon IIIa of the FGFR2 gene. This narrow spectrum of mutations was confirmed by other studies, since 284 out of the reported 288 Apert syndrome patients have one of these two mutations. ${ }^{4-13}$ It is important to point out that although mutation S252W was associated with a milder syndactyly than was P253R, all these patients had fusion of three or more digits in both hands and feet. ${ }^{10}$ These DNA alterations lie in the region linking the immunoglobulin (Ig)-like domains II and III of FGFR2, which is a highly conserved sequence among the different FGFRs. It has been proposed that the S252W and P253R substitutions alter the relative orientation of Ig-like domains II and III or the local conformation of the ligand binding site or both, and hence accentuate binding of fibroblast growth factors (FGFs). ${ }^{8}$ Oldridge $e t$ al ${ }^{14}$ have recently described three new mutations in residues 252 and 253; however, only one is associated with Apert syndrome, suggesting that the critical conformation of FGFR2 giving rise to this more severe phenotype also depends on specific amino acids at neighbouring sites.

The present finding of one of the canonical mutations of Apert syndrome not associated with severe syndactyly is intriguing, showing for the first time that $\$ 252 \mathrm{~W}$ may be associated with mild limb anomalies. Since the 5 ' end of exon IIIa of this patient has no other nucleotide alteration, this milder phenotype is not the result of changes in amino acids bordering residue 252. FGFR2 mutations seem to cause the phenotype according to a gain of function or dominant negative models. ${ }^{4}$ Therefore, we could speculate that this patient may have another mutation in some other gene, which is decreasing the function of the mutated FGFR2 molecule. The analysis of other genes in this particular patient, such as the ligands that bind to this receptor, would be important to improve our understanding of the function of FGFR2 as well as for the identification of the mechanisms causing limb malformations.

Variability of the clinical phenotype in subjects carrying the same mutation has been shown for other FGFR2 mutations as well as in other diseases..$^{74-20}$ Recently, Asher et $a l^{1}$ showed through genetic crosses between two mice species that the Pax3 mutation can produce distinct phenotypes depending on the genetic background. Interestingly, the nonApert patient reported here is of African Brazilian descent, suggesting that different racial backgrounds, which may reflect variability in some molecules that interact with FGFR2, might interfere differently in the expression of the mutated allele. It will be important to verify if there are other patients with these canonical Apert mutations and absence of severe syndactyly.

In addition to the difficulties in establishing a genotype-phenotype correlation for these conditions, as previously discussed, ${ }^{1622} 23$ the description of this patient provides further evidence for the existence of other factors (or genes) playing an important role in the determination of the phenotype.

The authors gratefully acknowledge the help of Constância Urbani, Antonia M P Cerqueira, Marta Canovas, Eloísa S Moreira, and Luís Alonso; Professor Marcus for allowing us to contact patients who are scheduled for plastic surgery; and Drs Mayana Zatz and Andrew Wilkie for valuable suggestions. This Mayana Zatz and Andrew Wilkie for valuable suggestions. This Pesquisa do Estado de São Paulo (FAPESP), Conselho Nacional de Desenvolvimento Cientíico e Tecnologico (CNPq), and Programa de Apoio ao Desenvolvimento Cientiico e Tecnologico (PADCT), PRONEX. The research of MRPB was supported in part by an International Research
Scholars grant from the Howard Hughes Medical Institute.

1 Cohen MM Jr. Craniosynostosis: diagnosis, evaluation and management. New York: Raven Press, 1986.

2 Gorlin RJ, Cohen MM, Levin LS. Syndromes of the head and neck. 3rd ed. Oxford: Oxford University Press, 1990:51939.

3 Kreiborg S, Cohen Jr MM. Epidemiologic, genetic and statistical aspects of Apert syndrome. Braz $¥$ Dysmorphol tistical aspects of Apert syndrome.
Speech-Hearing Disord 1997;1:67-72.

4 Wilkie AOM. Craniosynostosis: genes and mechanisms. Hum Mol Genet 1997;6:1647-56. 
5 Reardon W, Winter RM, Rutland P, Pulleyn LJ, Jones BM, Malcolm S. Mutations in the fibroblast growth factor receptor 2 gene cause Crouzon syndrome. Nat Genet 1994; 8:98-103.

6 Jabs EW, Li X, Scott AF, et al. Jackson-Weiss and Crouzon syndromes are allelic with mutations in fibroblast growth factor receptor 2. Nat Genet 1994;8:275-9.

7 Rutland P, Pulleyn LJ, Reardon W, et al. Identical mutations in the FGFR2 gene cause both Pfeiffer and Crouzon syndrome phenotypes. Nat Genet 1995;9:173-6.

8 Wilkie AOM, Slaney SF, Oldridge M, et al. Apert syndrome results from localized mutations of FGFR2 and is allelic with Crouzon syndrome. Nat Genet 1995;9:165-72.

9 Park WJ, Theda C, Maestri NE, et al. Analysis of phenotypic features and FGFR2 mutations in Apert syndrome. Am $\mathcal{f}$ features and FGFR2 mutation Genet 1995;57:321-8.

Hum Genet 1995;57:321-8.
10 Slaney SF, Oldridge M, Hurst JA, et al. Differential effects of Slaney SF, Oldridge M, Hurst JA, et al. Differential effects of
FGFR2 mutations on syndactyly and cleft palate in Apert syndrome. Am F Hum Genet 1996:58:923-32.

11 Hollway GE, Suthers GK, Hann EA, et al. Mutation detection in FGFR2 craniosynostosis syndromes. Hum Genet 1997;99:252-5.

12 Wada $C$, Ishigaki $M$, Toyo-Oka $Y$, et al. Nucleotide sequence at intron 6 and exon 7 junction of fibroblast growth factor receptor 2 and rapid mutational analysis in Apert syndrome. $\mathcal{F}$ p $\mathcal{F}$ Clin Pathol 1996;44:435-8.

13 Passos-Bueno MR, Sertié AL, Richieri-Costa A, et al. Description of a new mutation and characterization of FGFR1, FGFR2 and FGFR3 mutations among Brazilian patients with syndromic craniosynostosis. Am f Med Genet (in press).

14 Oldridge M, Lunt PW, Zackai EH, et al. Genotypephenotype correlation for nucleotide substitutions in the phenotype correlation for nucleotide substitutions in the 1997;6:137-43.
15 Meyers GA, Day D, Goldberg $R$, et al. FGFR2 exon IIIa and IIIc mutations in Crouzon, Jackson-Weiss, and Pfeiffer syndromes: evidence for missense changes, insertions and a deletion due to alternative RNA splicing. Am $\mathcal{F}$ Hum Genet 1996;58:491-8.

16 Gorry MC, Preston RA, White GJ, et al. Crouzon syndrome: mutations in two spliceoforms of FGFR2 and a common point mutation shared with Jackson-Weiss syndrome. Hum Mol Genet 1995;4:1387-90.

17 Passos-Bueno MR, Richieri-Costa A, Sertié A, Zatz M. A Pfeiffer mutation in an Apert patient: how wide is the specPfeiffer mutation in an Apert patient: how wide is the spectrum $\mathcal{F}$ Med Genet 1997;71:243-5.

18 La Spada AR, Wilson EM, Lubahn DB, Harding AE, Fischbeck KH. Androgen receptor mutations in X-linked spinal and bulbar muscular atrophy. Nature 1991; 352:77-

19 McPaul MJ, Marcelli M, Zoppi S, Griffin JE, Wilson JD. Genetic basis of endocrine disease: the spectrum of mutations in the androgen receptor gene that causes androgen resistance. 7 Clin Endocrinol Metab 1993;76:17-23.

20 Bellus GA Gaudenz $\mathrm{K}$ Zackar EH, et al. Identical mutations in three different fibroblast growth factor recepmutations in three different fibroblast growth factor receptor genes in autosomal dominant

21 Asher JH, Harrison RW, Morell R, Carey ML, Friedman TB. Effects of Pax 3 modifier genes on craniofacial morphology, pigmentation, and viability: a murine model of Waardenburg syndrome variation. Genomics 1996;34 285-98.

22 Cohen MM. Craniosynostoses: phenotypic/molecular correlations. Am f Med Genet 1995;56:334-9.

23 Winter RM, Reardon W. Lumpers, splitters and FGFRs. Am f Med Genet 1996;63:501-2. 